\title{
BODY MASS INDEX CORRELATES WITH AGE BUT NOT WITH SLEEP DURATION IN NEPALESE ADULTS
}

\author{
Amatya $\mathrm{M}^{1}$, Gorkhali $\mathrm{B}^{2}$, Islam $\mathrm{MN}^{3}$, Shrestha $\mathrm{S}^{4}$
}

\section{ABSTRACT}

INTRODUCTION: The problem of overweight and obesity has been recognized as public health problem worldwide. This study was done to measure incidence of overweight and obesity in Nepalese adult population and to explore correlation of body mass index (BMI) with sleep habits.

MATERIAL AND METHODS: BMI was calculated from measured height and weight; sleep habit information was gathered from participants' recall. Participants were grouped into 4 BMI classes and 3 sleep groups. Groups were compared for age, gender, and other variables by ANOVA and Chi square.

RESULTS: Of the total 241 participants, $72.2 \%(n=174)$ were male. Sleep duration was adequate for $80.2 \%$ participants; $37 \%$ were overweight, $5 \%$ were obese, and $1 \%$ were underweight. BMI had no correlation with sleep duration ( $\mathrm{p}$ value 0.753 ) but strongly correlated with age ( $\mathrm{p}$ value 0.000 ).

CONCLUSION: Incidence of overweight and obesity is high in the Nepalese adult population. BMI is not correlated to sleep duration in Nepalese population as reported for other countries.

KEY WORDS: Body mass index, Nepalese population, Sleep duration

1. PhD Scholar, Singhania University, Pacheri Bari, Jhunjhunu, Rajasthan, India

2. Department of Nursing, Nepal Medical College, Kathmandu, Nepal

3. Department of Physiology, Chitwan Medical College, Chitwan, Nepal

4. All Nepal College of Technical Education, Chabahil, Kathmandu, Nepal

\author{
For Correspondence \\ Binu Gorkhali \\ Department of Nursing, \\ Nepal Medical College, \\ Kathmandu, Nepal \\ E-mail:binukhusi@yahoo.com
}




\section{INTRODUCTION}

Overweight and obesity is an excessive amount of body fat and is usually expressed by BMI which is calculated by dividing the weight of an individual in kilograms $(\mathrm{Kg})$ by his/her height given in meter square $\left(\mathrm{m}^{2}\right){ }^{1}$ 'The ideal body weight of an individual would be a BMI between 18.5 to 24.99 $\mathrm{Kg} / \mathrm{m}^{2}$; BMI $>25$ to $30 \mathrm{Kg} / \mathrm{m}^{2}$ would be considered as overweight and BMI $>30 \mathrm{Kg} / \mathrm{m}^{2}$ would be considered as obese. ${ }^{2}$ The problem of overweight and obesity has been recognized as public health problem worldwide due to the fact that it increases the risk of several disorders such as hypertension, coronary artery disease and stroke, respiratory effects, arthritis, psychological effects, and some cancers. ${ }^{3}$ The results affect the individual's life expectancy and the national productivity on the long run. The burden of overweight and obesity is very high among developed countries such as the USA. ${ }^{4}$ Recently, incidence of overweight and obesity is increasing even in the developing countries like Nepal.

Much has been learned regarding regulation of body weight recently, but the prevalence of obesity continues to rise. Individual and environmental factors that have an influence on energy balance are not fully understood. Recently, several studies have found an association between reduced sleep duration and increased weight in adults as well as adolescents and children, suggesting that short sleep duration correlates with an increased risk of being overweight or obese ${ }^{6-10}$ A sleep of 7-9 hours in night is recommended for an adult person and more for younger. ${ }^{11}$ However, over the past 40 years, daily sleep duration in the United States population has decreased by 1.5 to 2 hours $^{7}$ and the same may be true for most other countries and societies also.

Reports on the body fat composition of the general population of Nepal are few. One study has reported a prevalence of overweight and obesity to be $32.9 \%$ and $7.2 \%$ respectively among the adult males of Dharan city in Eastern Nepal ${ }^{12}$ where as Sharma ${ }^{13}$ reported nearly $35 \%$ of the male population of the age group 25-60 years to be overweight or obese. Another study involving females attending a general gynecological clinic has reported $37.3 \%$ women to be overweight and $8 \%$ obese. ${ }^{14}$ Studies exploring obesity risk factors in the general Nepalese population have not been reported to date. This study aims to measure the BMI and determine the sleep habits of general adult population of Nepal and to assess if the negative correlation of sleep duration to BMI holds true for this population.

\section{MATERIALAND METHODS}

A cross sectional, descriptive study was conducted in the one month period in August, 2014 among the general population in Kathmandu, the capital of Nepal. The study was conducted in the locality of the Exhibition Road, Kathmandu, Nepal-an area where several colleges (government as well as private), a hospital, the Central Blood Bank, business houses, a fun park, and the city bus park terminal are located closely. Apparently healthy and consenting adult people of either sex were randomly selected and recruited by mixed lottery and convenience sampling methods.

A pre-tested questionnaire was used to collect information on general characteristics and sleep habits. Weight in $\mathrm{Kg}$ and height in centimeters $(\mathrm{cm})$ were measured by using a digital weight scale and a wallmounted height scale respectively, to the nearest 0.5 multiple. Both were measured in comfortable clothes and without shoes. Age below 18 years or above 60 years, recent history of any illness, and past history of metabolic, cardiovascular, respiratory, digestive, or other disorders, and current use of any medication were the exclusion criteria. BMI was calculated. Based on BMI, participants were grouped into four categories: underweight (BMI < 18.5), normal (BMI range 18.524.9), overweight (BMI range 25-29.9) and obese (BMI $\geq 30)$. ${ }^{2}$ Participants were also grouped as those having less sleep ( $<7$ hours), adequate sleep (7-9 hours), and more sleep ( $>9$ hours). ${ }^{11}$ Software Microsoft Excel 2007 was used for data entry, calculation, and presentation. Software SPSS version 11.5 was used for data analysis. Means, standard deviations, and frequency tables were used for continuous and categorical variables. Groups were compared by ANOVA and Chi square and strength of correlation was determined by Pearson's correlation coefficient with levels of significance set at $95 \%$.

\section{RESULTS}

From a total of 241 participants, age information was provided by 232 individuals ( $3.7 \%$ missing), BMI could be calculated for 202 individuals( $16.2 \%$ missing), and sleep duration could be calculated for 213 individuals (11.6\% missing). Males comprised $72.2 \%(\mathrm{n}=174)$ and females comprised $27.8 \%(\mathrm{n}=67)$. Table 1 shows the age distribution, sleep duration hours, anthropometric measurements, and BMI of the participants. 
Table 1: General characteristics of the participants

\begin{tabular}{|l|l|l|l|l|}
\hline Characteristics & Means \pm SD & Min & Max & Range \\
\hline Age in years completed & $29.21 \pm 8.4$ & 16 & 54 & 38 \\
\hline Sleep duration hours & $7.83 \pm 1.02$ & 4.0 & 11.0 & 10.0 \\
\hline Height in meters & $1.63 \pm 0.1$ & 1.40 & 1.85 & 0.45 \\
\hline Weight in kilograms & $64.72 \pm 10.81$ & 41.0 & 91.5 & 50.5 \\
\hline Body mass index $\left(\mathrm{kg} / \mathrm{m}^{2}\right)$ & $24.3 \pm 3.1$ & 18.06 & 32.89 & 14.82 \\
\hline
\end{tabular}

A combined two-fifth of the population was overweight or obese and more than one-third was overweight. (Figure 1)

\section{Figure 1: Percentage distribution of BMI categories}

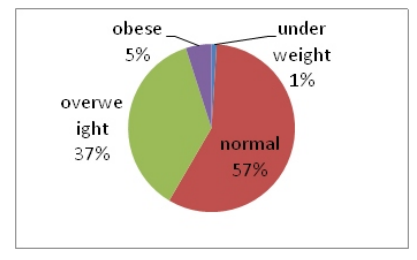

Most people had an adequate amount of night sleep, which is of 7-9 hours. (Table 2)

Table 2: Distribution of BMI among groups having different sleep duration

\begin{tabular}{|l|l|l|l|l|l|}
\hline \multirow{2}{*}{$\begin{array}{l}\text { Groups by adequacy } \\
\text { of sleep hours }\end{array}$} & \multicolumn{4}{|c|}{ Category of body mass index } & \multirow{2}{*}{ Total } \\
\cline { 2 - 5 } & Underweight & Normal & Overweight & Obese & \\
\hline Less than 7 hours & 0 & 9 & 6 & 1 & $16(7.9 \%)$ \\
\hline Adequate (7-9 hours) & 1 & 94 & 59 & 8 & $162(80.2 \%)$ \\
\hline More than 9 hours & 1 & 13 & 9 & 1 & $24(11.9 \%)$ \\
\hline Total & 2 & 116 & 74 & 10 & $202(100 \%)$ \\
\hline
\end{tabular}

The different BMI groups were compared against sleep groups. Chi-squared comparison showed no significant difference ( $\mathrm{p}$ value 0.811 ). The correlation between sleep hours and BMI measurements was also not significant, the Spearman's correlation coefficient being 0.022 ( $\mathrm{p}$ value $0.753)$.

Taking into consideration the difference in social responsibilities and characteristics of the two sexes, male and female groups were compared by ANOVA.(Table 3 )

Table 3: Gender-wise comparison of sleep habits and BMI

\begin{tabular}{|l|l|l|l|l|l|}
\hline Gender & $\begin{array}{l}\text { Age(yr) } \\
\text { Mean } \pm \text { SD }\end{array}$ & $\begin{array}{l}\text { Time to } \\
\text { bed } \\
\text { Mean } \pm \text { SD }\end{array}$ & $\begin{array}{l}\text { Wake up } \\
\text { time } \\
\text { Mean } \pm \text { SD }\end{array}$ & $\begin{array}{l}\text { Sleeping } \\
\text { hours } \\
\text { Mean } \pm \text { SD }\end{array}$ & $\begin{array}{l}\text { BMI (kg/m2) } \\
\text { Mean } \pm \text { SD }\end{array}$ \\
\hline Male & $29.34 \pm 8.374$ & $10.15 \pm 1.08$ & $5.96 \pm 1.18$ & $7.74 \pm 1.02$ & $24.5 \pm 2.88$ \\
\hline Female & $28.84 \pm 8.537$ & $9.59 \pm 0.98$ & $5.64 \pm 0.77$ & $8.06 \pm 1.00$ & $23.83 \pm 3.53$ \\
\hline P values & 0.687 & 0.000 & 0.046 & 0.036 & 0.164 \\
\hline
\end{tabular}

bed earlier, woke up earlier, and had a longer night sleep than the males (all differences statistically significant). But the body mass index was not significantly different.

\section{DISCUSSION}

The role of sleep on BMI is being widely explored mostly in developed countries but fewer studies have been conducted in less-developed countries. In this study, we have reported the BMI of a sample population from the capital city of Nepal based on measured height and weight of participants. We have also documented the sleep habits of the participants and explored its relation with BMI. This is the first report on sleep habits of Nepalese population and also its correlation with BMI.

This study found a high incidence of overweight and obesity in the Nepalese adult population, which has been reported by other studies as well. ${ }^{12-14}$ This study also provides a cross sectional picture of the general sleep habit of Nepalese people. Most of the participants had adequate duration of night sleep. A correlation between sleep hour duration and BMI did not exist in the Nepalese people which is a different finding from other referred studies.

The different BMI groups were compared by ANOVA for age, gender, and sleep habits (data not shown). A difference of borderline significance ( $p$ 0.052) was observed for gender, male having higher BMI. A very highly significant correlation existed between age and BMI ( $\mathrm{p}$ value 0.000 ). In a previous study involving 355 Nepalese medical students, we had reported a low incidence of overweight $(4.23 \%)$ and obesity $(0.3 \%){ }^{15}$ Considering the younger age of college students (mean age in years $20.35 \pm 1.73$ ), the finding is in agreement with the present study. BMI correlates strongly with sedentary behaviors ${ }^{16}$ and the lifestyle of the Nepalese adults may be responsible for the correlation with BMI because generally Nepalese people are less involved in non-sedentary activity with increasing age.

Most other cross-sectional studies of the type were based on over-the-phone interview or questionnaire. In this study, the information about age and sleep habits were based on the participants' memory recall and also willingness but the height and weight of participants were measured by trained observers. This adds to the validity and reliability of the study. However, the sample 
population included mostly the more active individuals because the study was conducted in a busy mid-city location. Increasing the sample size, better representation of the sexes, and household approach are recommended for future studies to better meet the objectives.

\section{CONCLUSION}

The incidence of overweight and obesity is fairly high in the Nepalese adult population and $1 \%$ of the population is underweight. A correlation of sleep duration with BMI was not found as has been reported in most other studies but a strong correlation with age was observed. This study reports for the first time the sleep habits and its correlation with BMI in the Nepalese adult population. Most people have adequate night sleep. Nepalese women sleep earlier, wake up earlier, and sleep longer than the men.

\section{REFERENCES}

1. James $M L$, Donald $C Y$, Joseph AR, Ronald MD. Obesity: assessment and management in primary care. Am Fam Physician. 2001;63:2185-97.

2. World Health Organization. Obesity: preventing and managing the global epidemic. Report on a WHO consultation.Technical Report Series No 894;2000. WHO, Geneva, Switzerland.

3. Haslam DW, James WP. Obesity. Lancet. 2005;366:11971209. bhttp://dx.doi.org/10.1016/S0140-6736(05)674831

4. Flagel KM, Caroll MD, Kuczmarski RJ, Johnson CI. Overweight and obesity in the United States 1960-1964. International Journal of Obesity and related Metabolic Disorders. 1998;22: 39-47.

5. Vaidya A, Shakya S, Krettek A. Obesity prevalence in Nepal: public health challenges in a low-income nation during an alarming worldwide trend. Int $J$ Environ Respublic Health. 2010;7:2726-44.http://dx.doi.org/10.3390/ijerph7062726P Mid:20644698 PMCid:PMC2905575

6. Wendt EM, Pernerstorfer E, Mosendeder J, Karner G. Association between sleep duration and body-mass-index in10-to14-year-old Austrians. ErnaehrungsUmschau International. 2013;60(8):140-144. DOI: 10.4455/eu. 2013. 025.

7. Chaput JP, Despres JP, bouchard C, Tremblay A. The association between sleep duration and weight gain in adults: $a$ 6-year prospective study from the Quebec Family Study. SLEEP. 2008;31(4):517-23.PMid: 18457239 PMCid:PMC 2279744
8. Ozturk A, Mazicioglu MM, Poyrazoglu S, Cicek $B$, Gunay $O$, Kurtoglu $S$. The relationship betweensleep duration and obesity in Turkish children and adolescents.ActaPaediatrica.2009;98:699-702. DOI:10.1111/j.1651-2227.2008.01169.x.http://dx.doi. org /10.1111/j. 16512227.2008.01169.x

9. Garaulet M, Ortega FB, Ruitz JR, et al. Short sleep duration is associated with increased obesity markers in European adolescents: effect of physical activity and dietary habits. The HELENA study. International Journal of Obesity.2011;35:1308-1317. DOI: 10.1038/ijo. 2011. 149. http://dx.doi.org/10.1038/ijo. 2011.149

10. Magee C, Caputi P, Iverson D. Lack of sleep could increase obesity in children and too much television could be partly to blame.ActaPaediatrica.2014;103:e27-e31. DOI: 10.1111/apa.12447.http://dx.doi.org/10.1111/apa. 12447

11. Sleep Health Foundation. Sleep needs across the lifespan. e-Brochure. 2011.www.sleephealthfoundation.org.au.

12. Vaidya A, Pokharel PK, Nagesh S, Karki P, Kumar S, Majhi S. Association of obesity and physical activity in adult males of Dharan, Nepal. Kathmandu University Medical Journal. 2006;4:192-97.

13. Sharma I. Tailoring the body mass index cutoff for overweight amongst the Nepalese male population. International Journal of Medicine and Medicinal Science. 2013;5:546-49.

14. Padhye SM. A study of body mass index (BMI) of Nepalese women attending gynecology clinic. J Nepal Med Assoc. $2007 ; 46$ (4):185-8.PMid:18340371

15. Amatya M, Khanal B, Yadav SR. Body mass index of Nepalese medical students: a cross-sectional study. International Journal of Development Research. 2014; 4(3): 746-48.

16. Salmon J, Crawford D, Timperio A, Owen N. The association between television viewing and overweight among Australian adults participating in varying levels of leisure-time physical activity. International Journal of Obesity. 2000;24:600-06.http://dx.doi.org/10.1038/sj. ijo.0801203PMid:10849582 